
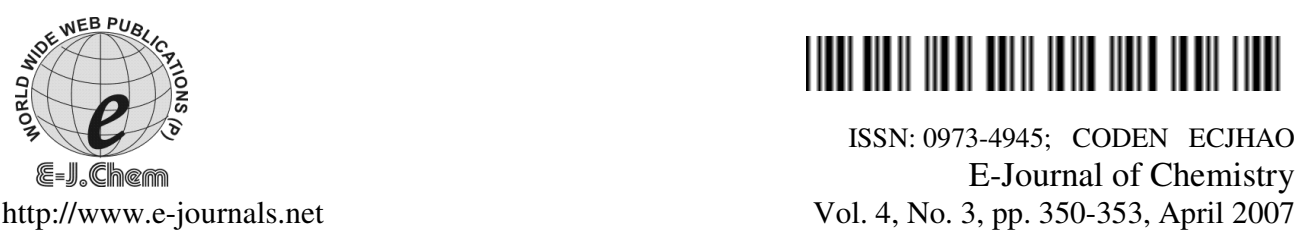

\title{
Effect of Additives on Some Physical Parameters of Palm Oil
}

\author{
N. O. EDDY* and A. S. EKOP \\ Department of Chemistry \\ University of Uyo, Uyo, Nigeria \\ E-mail: nabukeddy@yahoo.com
}

Received 27 November 2006; Revised 29 December 2006; Accepted 5 January 2007

\begin{abstract}
Effect of additives (carrot, lime, paw paw and red dye) on the density, viscosity, moisture content and melting point of palm oil (PO) was investigated by dissolving $1 \mathrm{~g}$ of each additive to $10 \mathrm{~mL}$ of pre-analysed oil in a beaker. The mixture was heated and their their moisture content,melting point, viscosity and density were determined. The result of the analysis shows that all the additives significantly increased the density, moisture content and viscosity (except lime) of the oil. Addition of paw paw and red dye also increased the melting point of the oil while the addition of carrot and lime juice decreased the melting point of the oil.
\end{abstract}

Keywords: Palm oil, Physical constants, Effect of additives.

\section{Introduction}

Eleasis guinensis is a major specie of oil bearing plants cultivated in Nigeria and most other countries of the world. Although oil palm originated from the tropical rain forest region of West Africa, it has spread from $16^{\circ} \mathrm{N}$ latitude of Senegal to $15^{\circ} \mathrm{S}$ in Angola and Eastwards to Indian Ocean, Zarizibar and Malaysia. The yield of oil palm is higher than that of other oil seed crops per unit area, producing $2.5 \mathrm{~mL}$ oil per hectare per year ${ }^{1}$. Numerous studies has been conducted on the food, industrial and medicinal uses of palm oil .

According to Offem et al., ${ }^{3}$ food additives is any substance which is not a normal constituent of the food stuff and whose purposeful addition is aimed at technological, organoleptic or nutritional functions. Eddy et al., ${ }^{2}$ stated that additives are chemical substance deliberately added to food stuff or food materials in known and regulated quantity 
for the purpose of assisting in processing, preservation, improving flavour, texture or appearance of food. This implies that some additives may be reactive, inactive, nutritive, and non-nutritive but it is recommended that they should neither be toxic nor hazardous ${ }^{4}$.

James $^{5}$ stated that the quality of palm oil can be assessed by analyzing the oil for their chemical and physical constants. The effect of additives on the chemical composition of palm oil has been studied by Eddy et al., ${ }^{2}$ and they found that some additives can alter the chemical constituent of palm oil. Studies on the effect of additives on the physical parameters of palm oil are scanty. The present study is aimed at finding the effect of these additives on the physical parameters of palm oil. The result of such study can form a baseline for evaluation of the average effects of these additives on palm oil quality.

\section{Experimental}

\section{Materials and methods}

Pure sample of palm oil was obtained from NIFOR (Nigerian Institute for Oil Palm Research) in Abak. From the bulk oil, $10 \mathrm{~mL}$ of the oil was respectively measured into five different plastic containers. To each of the container, $1 \mathrm{~g}$ of each additives (paw paw, carrot, Congo red dye, lime) were added and each oil -additive mixture was stirred and warm to ensure even mixing.

The melting point of the oil was determined by using melting point apparatus. The viscosity of the oil was measured by using a viscometer that operates on stoke's principles ${ }^{6}$. The relative density of the oil was measured by using a density bottle and the moisture content of the oil was determined by the oven drying method ${ }^{7}$.

\section{Results and Discussion}

Table 1 shows the density, viscosity, moisture and melting point of the oil before and after the introduction of the different additives. The density of the palm oil (PO) was found to be 0.8940. When the palm oil was mixed with carrot (POC), paw paw (POP) lime (POL), and dye (POD) the densities were $0.8965,0.8954,0.8980$ and 0.901 respectively.

The moisture content of PO was $0.23 \%$. When the PO was mixed with carrot, paw paw, lime and dye, the moisture content of POC, POP, POL and POD were $0.79 \%, 10.40 \%$, $0.48 \%$ and $0.43 \%$ respectively.

The melting point of PO was $39.740 \mathrm{C}$. When the oil was mixed with carrot (POC), paw paw (POP), lime (POL) and red dye (POD) the melting point were $33.26{ }^{\circ} \mathrm{C}, 41.56{ }^{\circ} \mathrm{C}$, $25.62{ }^{\circ} \mathrm{C}$ and 46.41 respectively ${ }^{0} \mathrm{C}$.

Density is one of the most important physical parameters that affect or specify oil quality. According to Etuk ${ }^{10}$ density is a useful aid in controlling hydrogenation and blending of fat. Ukpong ${ }^{12}$ also stated that density of oil is an indicator or index of its total solid content.

The observed value for the density of PO was comparable to the range of values reported by $\mathrm{Umoh}^{8}$. According to Swern ${ }^{9}$, the density of palm oil is strongly influence by polymorphism of the oil, crystalline formation, mutual stability of the glycerides, conditions of heating and cooling. Consequently, since heating and cooling were observed during the mixing of the oil with the respective additives, changes in the crystalline form and mutual stability of the glycerides must have taken place leading to the observed difference between the density of PO/POL, PO/POP, PO/POD and PO/POC.

Eddy et al., ${ }^{2}$ also stated that the degree of unsaturation and average molecular weight of the oil may alter the density of the oil. Therefore the introduction of additives to the palm oil 
can alter its degree of unsaturation and molecular weigh. Also, differential increase in the amount of the total solid content of the oil might have been responsible for the difference between the densities of PO and the other samples. Generally, triglycerides are affected by heating and the homogenous phase created after the mixing and heating suggests that the inherent constituents of the additives can alter the ratio, mass: volume and thus the density of the oil-additive mixtures. Variation in the constituents of the different additives implies that the constituents and densities oil-additive mixtures will also vary.

There was a slight increase in the viscosity of PO when the various additives were mixed with the oil except for POL (6.589). The increase was highest for POD (6.996) and least for POC (6.78). However, addition of lime juice lowers the viscosity of the PO by an approximate value of about 0.065 . According to Ukpong $^{12}$, the viscosity of oil depends on the length of the fatty acid chain of the oil, degree of saturation of the oil and the formation of polymeric materials. Therefore, the increase in viscosity when the PO was mixed with carrot, paw paw and dye can be attributed to increase in the carbon length of the fatty acid molecule, increase in the degree of unsaturation of the oil and the formation of polymeric materials when the additives are added to the palm oil. Also, Bailey ${ }^{13}$ also stated that high molecular weight fatty acid is more viscous than low molecular weight fatty acids. Viscosity is a measure of the frictional force in a liquid ${ }^{14}$. And the degree of viscous drag depends on the density of the liquid implying that the denser a liquid, the higher its viscosity. This is account for the measured relative values for the viscosities of the different oil additive mixtures.

Moisture is another physical constant that can be used in characterizing palm oil. According to James 15 the moisture content of any food materials is an index of stability and susceptibility to fungal infection. Literatures also confirm that plant and animal materials contain moisture in significant proportion ${ }^{11,16,17}$ Therefore, the observed increase in the moisture content of PO when carrot, paw paw, lime and dye were added to the oil can be attributed to the combination of the inherent moisture content of the plant materials and that of the PO. The increase was very prominent in paw paw where there was a 4421.739 percentage increase in moisture content. This is in accordance with literature. According to Umoh 8, the moisture content of paw paw ranges from 87.29 to $91.02 \%$ which explain the highest increase in moisture been found in POP.

Melting point is one of the physiochemical parameters that are often used characterized palm oil. Paw paw and red dye has the potential of increasing the melting point of PO. Melting point is a molecular property implying that paw paw and dye can decrease molecular motion in PO as confirmed by the increased viscosity and the respective melting points of POD and POP. For the same reason, lime and carrot decreased the melting point of POL because the molecular motion is increased by the addition of lime and carrot juice. Lime can react chemically with oil and break the fat and oil molecules of the oil due to its strong acidity ${ }^{2}$. This could also be responsible for the decreased in melting point of the oil when lime was added.

Table 1. Physical parameters of the oil

\begin{tabular}{llllll}
\hline Parameters & PO & POC & POP & POL & POD \\
\hline Density at $30{ }^{\circ} \mathrm{C}$ & 0.8940 & 0.896 & 0.8954 & 0.8980 & 0.901 \\
Viscosity at $30{ }^{\circ} \mathrm{C}\left(\mathrm{x} 10^{3}\right)$ & 6.66 & 6.78 & 6.83 & 6.60 & 6.70 \\
$\%$ Moisture content & 0.23 & 0.79 & 10.43 & 0.48 & 0.43 \\
Melting point $\left({ }^{\circ} \mathrm{C}\right)$ & 39.74 & 33.26 & 41.56 & 26.62 & 46.41 \\
\hline
\end{tabular}




\section{Conclusions}

From the results of this study, it can be remarked that the addition of $1 \mathrm{~g}$ of carrot, lime, dye and paw paw juice can alter the moisture content, melting point and viscosity of the oil therefore an introduction of carrot, paw paw, lime and dye may affect physical quality of red palm oil.

\section{Acknowledgement}

The authors are grateful to Mrs Edikan Nnabuk Eddy for typing the manuscript and to Mr. B. A. Etuk

\section{References}

1. Earp D A and Newall W, International development in palm oil. The incorporated society of Patens, Kuala, Malaysia, 1976, 200.

2. Eddy $\mathrm{N}$ O, Ekop A $\mathrm{S}$ and Etuk B A, Effect of additives on the Chemical composition of palm oil. AJFAND report, 2006, 325.

3. Offem J O, Moma E E, Onuchukwu, A and Onuoha N J. Chem. Soc. Nig. 2003, 28, 92.

4. Divine $\mathrm{J}$ and Williams $\mathrm{P}$, The chemistry and technology of edible oil and fat. I Ed. Pergamon press, London, 1961, 14

5. James C S, Analytical chemistry of food. Blackie academic and Professional, London, 1984, 150.

6. Atkin P W, Physical chemistry, $4^{\text {th }}$ Ed. ELBS with Oxford University press, London, 1990, 450.

7. A O A C, Official Methods of Analysis, Association of Official Analytical Chemists, $12^{\text {th }}$ Ed. William H. Ed., 1984, 12.

8. Umoh I B, Commonly used fruits in Nigeria. In Nutritional quality of plants food. Osagie, A U and Ekpa, O U Ed, Post Harvest research unit, Benin, Nigeria, 1998.

9. Swern D, Bailey's industrial oil and fat products. $2^{\text {nd }}$ Ed. John Willey and sons, London, 1979

10. Etuk B A, Effect of some local additives on the chemical composition of palm oil. M.Sc. Thesis. University of Uyo, 2006, 120.

11. Onimawo A I and Egbekun M K, Comprehensive food science and nutrite.Revised edition; Nigeria, 1998, 87

12. Ukpong $\mathbf{J}$, Chemical composition of the seeds of flutted pumpkin and cashew nut. M.Sc. Thesis. University of Uyo, Uyo, 2006, 89.

13. Bailey A E ,Industrial oil and fat products. $2^{\text {nd }}$ Ed. Interscience Publishers, New York, 1956, 216.

14. Sharma K K and Sharma L K ,A textbook of physical chemistry. $4^{\text {th }}$ Ed., Vikas pub. House PVT LTD, 2004, 187.

15. Eneobong $\mathrm{H}$ N, Eating Right, A Nutritional Guide. University of Calabar press, Calabar, Nigeria, 2001, 269.

16. Aurand L W and Woods A E, Food Chemistry. Westport, Connecticut. The Avi Pub. Comp, inc, London, 1975, 356.

17. Lee R A, Basic food chemistry. $2^{\text {nd }}$ Ed. The AVI Publishing Inc, Westport, Connecticut, 1983, 459. 


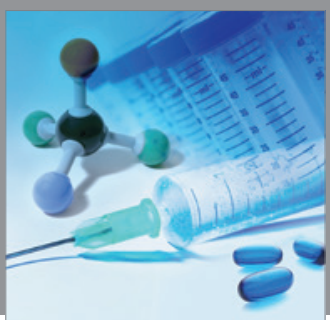

International Journal of

Medicinal Chemistry

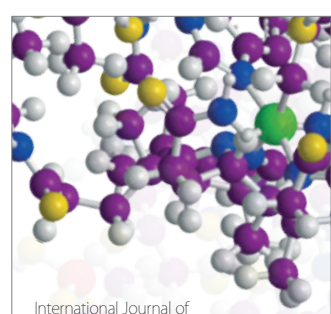

Carbohydrate Chemistry

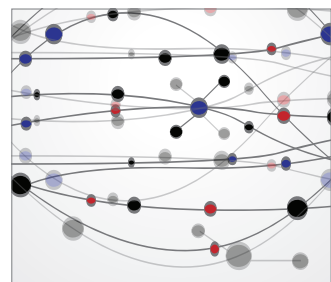

The Scientific World Journal
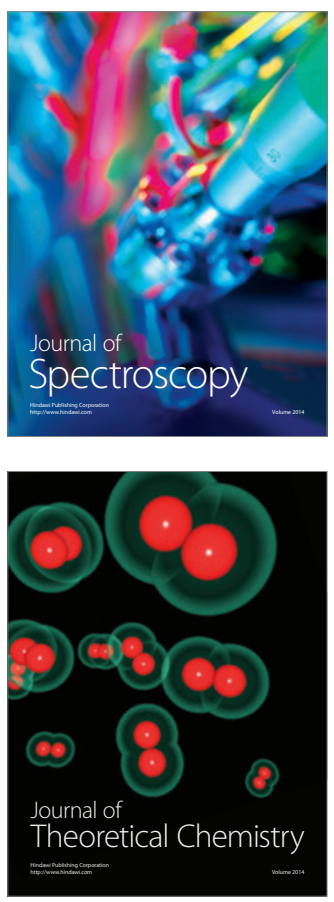
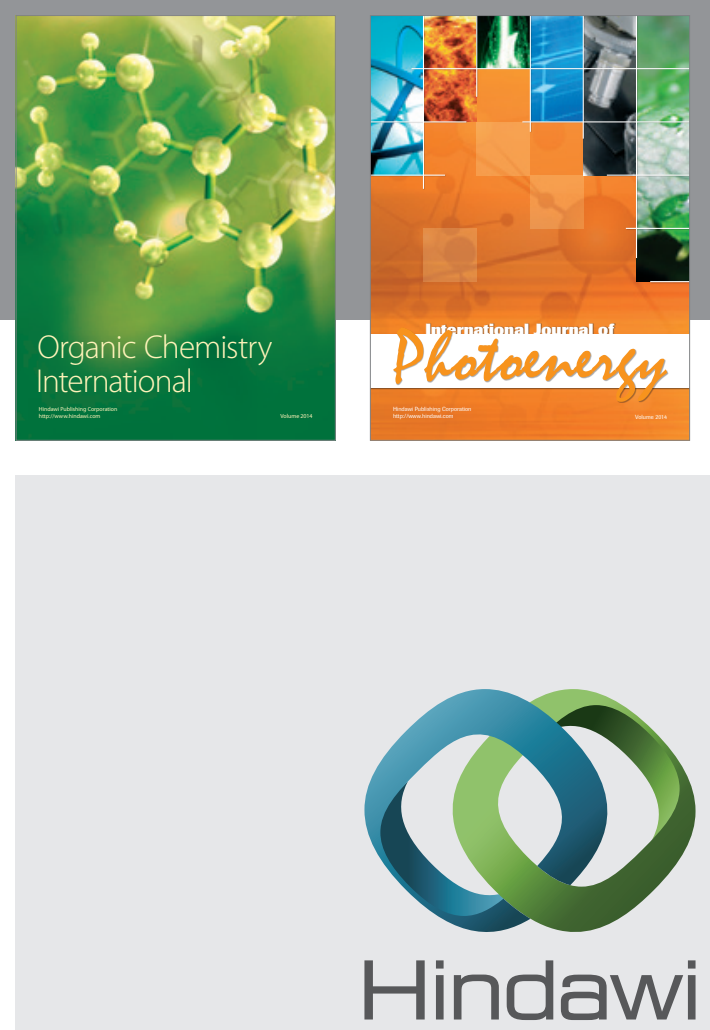

Submit your manuscripts at

http://www.hindawi.com
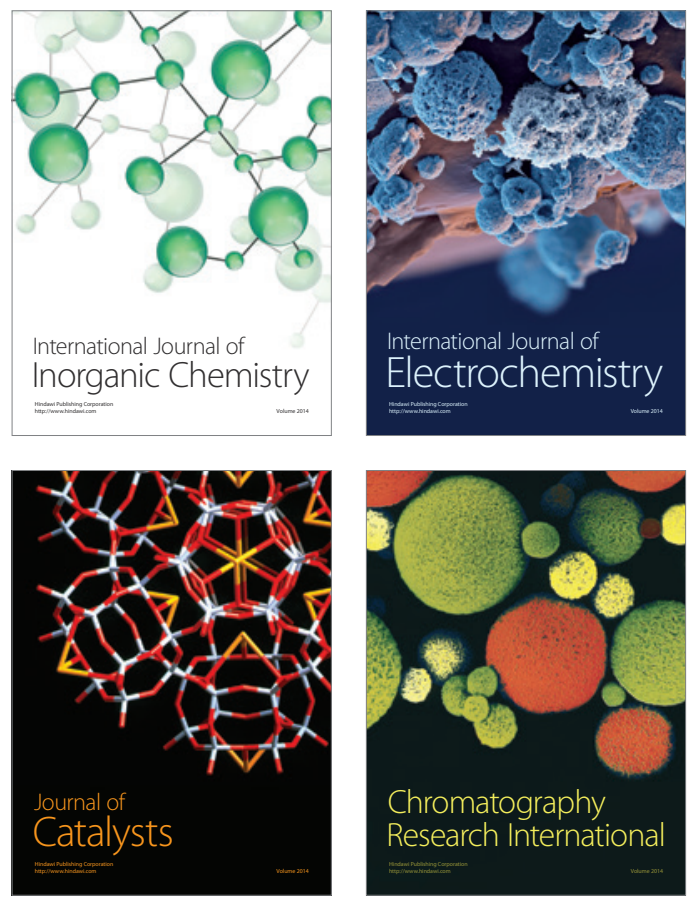
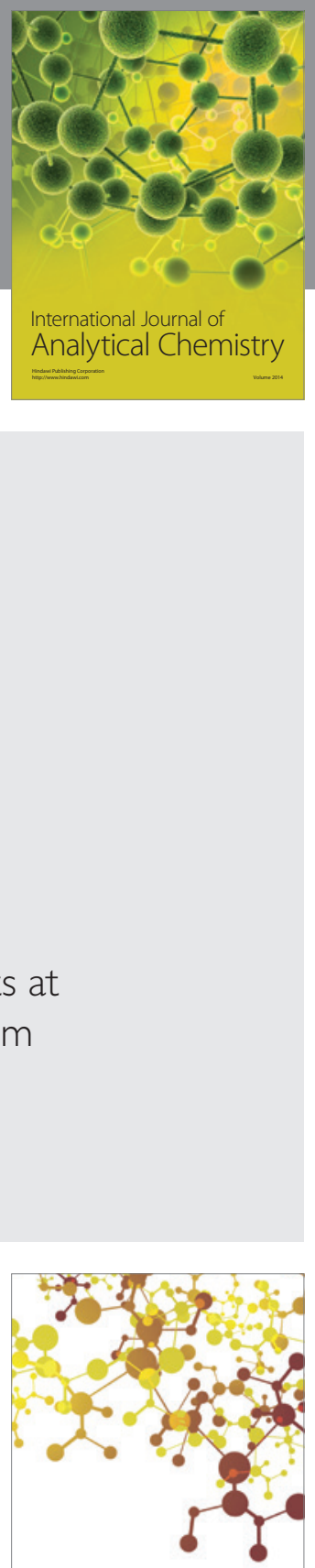

Journal of

Applied Chemistry
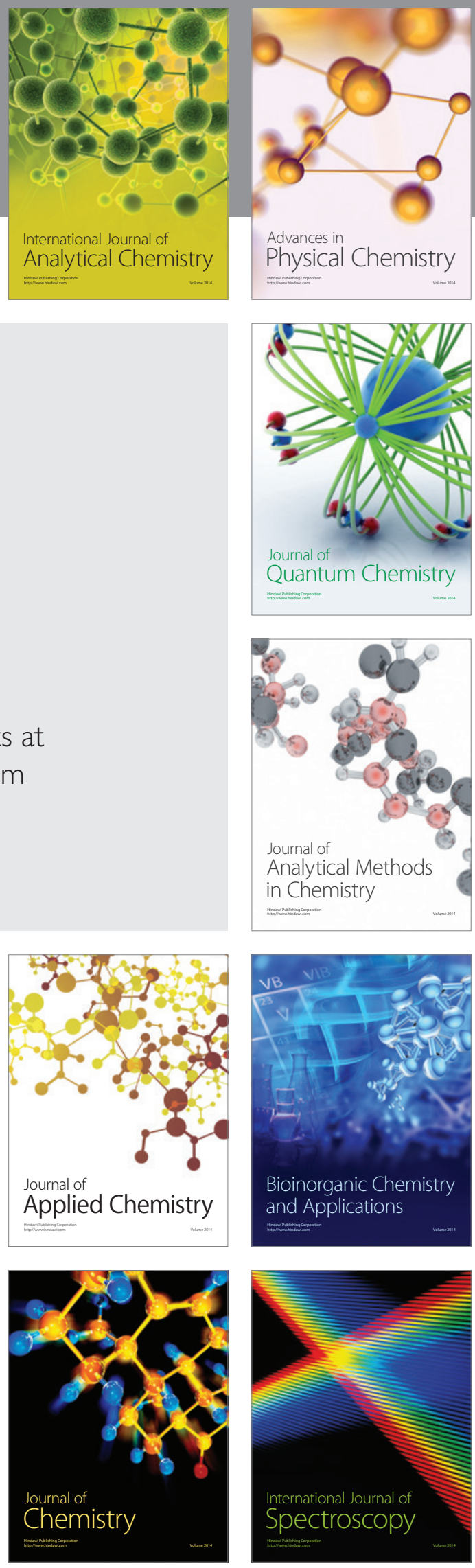